\title{
V wie Vergangenheit mit Vorsicht
}

Dominik Heim

Korrespondenz: PD Dr. med. Dominik Heim Chefarzt Chirurgie Spital Frutigen CH-3714 Frutigen

dominik.heim[at]spitalfmi.ch
Anfang Dezember kam sie in die Kinos, die Neuverfilmung der Anna Karenina. Krieg und Frieden mit Tolstoi in Verbindung zu bringen, liegt auf der Hand. Bei Anna Karenina geht der Gedankengang vielleicht eher über Greta Garbo, die «Göttliche» in der Rolle der Karenina, bis man sich des gleichen bestimmende Element sei, bestechend (und wohl zutreffend).

Remakes erlauben es auch jüngeren Zeitgenossen, Nicht-Bekanntes (weil damals noch nicht geboren) $\mathrm{zu}$ entdecken und auf der Suche nach der Vergangenheit auf das Original zu stossen. Es gibt unzählige

\section{Als ältere Ausbildner sind wir verpflichtet, auch das «Alte» weiter- zugeben, damit neue Trends in ihren Anfängen und in ihrer Logik verstanden werden können.}

Autors gewahr wird. Und man erinnert sich, wie man damals - im burgunderroten Plüschsessel im Kino Piccadilly am Bahnhof Stadelhofen - diesen Schwarzweiss-Film mit viel weissem Rauch aus der Lokomotive in der Schneelandschaft und im schwarznassen Bahnhof von Russland genossen hat. Der Regisseur sei das Wichtige in einem Film und nicht der Schauspieler, war damals die vorherrschende Meinung, aber das konnte bei der Garbo eigentlich gar nicht stimmen. Jetzt also ist es Keira Knightley, die diese Figur entgegen der sympathischen, mitleiderregenden Darstellung in früheren Filmen hier auch als «Biest» mit einer «animalischen Unberechenbarkeit» interpretiert. Dass die Sympathie im Zuschauer dann doch überwiegt, muss so sein (wer liebt schon das Negative in einer mitleiderheischenden Kultfigur?). Schliesslich «soll es dem Zuschauer nicht egal sein, wenn sie sich am Ende unter den Zug wirft» (Sonntagszeitung vom 25.11.2012).

Remakes wie Anna Karenina haben eine lange Tradition in der Kultur. Unsterbliche Figuren sterben (es erinnert an die Halbgötter - bei denen man aber zuerst die Achillesferse finden muss - und erinnert an unseren Berufsstand, wo aus ehemaligen Göttern jetzt Halbgötter in Weiss wurden) und erscheinen in neuer Interpretation mit Charisma und emotionaler Wucht wieder aus der Asche oder Versenkung. Glüht die Asche aber nur ganz leicht, dann wird es das Schicksal des ein-maligen 007 George Lazenby (On Her Majesty's Secret Service, 1969). Das sei aber bei Skyfall (2012) nicht der «fall». Film und David Craig seien (noch) besser als A Quantum of Solace (2008), sagen die Kritiker. Und dabei war doch schon die Idee, dass das Wasser und nicht das Öl das zukunfts-
Song-Versionen von Caravan, darunter auch jene von Duke Ellington, selbst diese liegt aber sehr weit zurück. Jetzt aber kommt das Lied wieder auf der neuen CD The Duke (2012) - eine zeitadaptierte Liedversion und faszinierende Hommage von Joe Jackson an Ellington. Eine meisterhaft orchestrierte, «kalt den

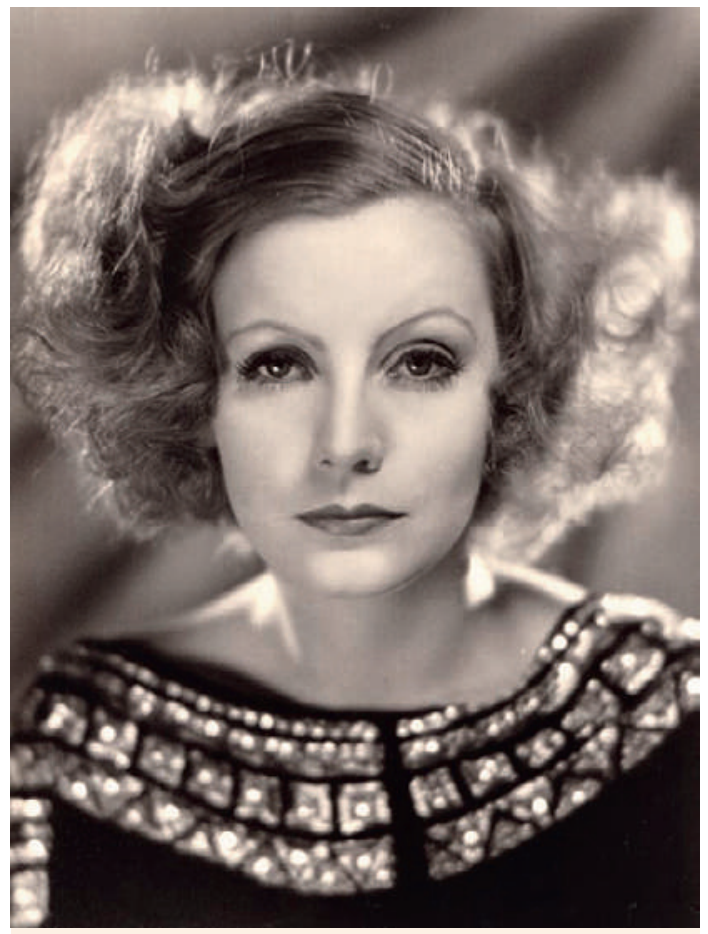

Die Göttliche: Greta Garbo war die erste Anna Karenina und fegte die Ansicht hinweg, der Regisseur sei das Wichtigste an einem Film. 


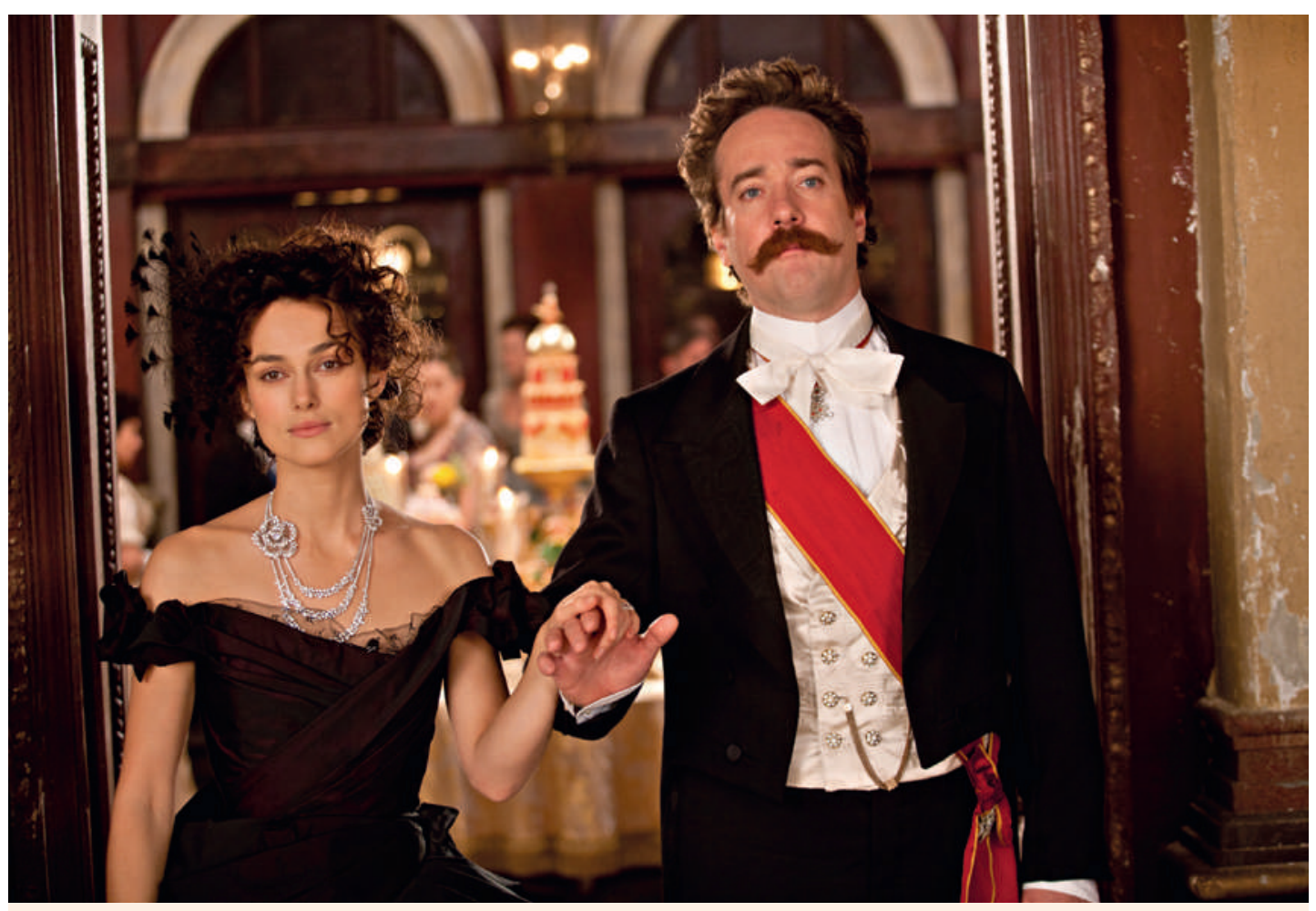

Die Nachfolgerin der Garbo: Keira Knightley - auch schön, in ihrer Rolle aber eher ein Biest.

(@ Focus Features)

Rücken herunterlaufende» Hommage ist auch die an Leidenschaft kaum zu überbietende Interpretation der nie verstummten Chansons von Edith Piaf durch Patricia Kaas (Kaas chante Piaf 2012). Hier wird die fragile, die traurig-volle Stimme des Spatzes von Paris mit der lasziven Emotionalität einer Patricia Kaas intensiviert - «je ne regrette rien» in Perfektion!

Und der Bezug zur Medizin? «Früher haben wir ... war alles anders ... war alles besser ... ja, früher!». Damit werden die 50-Stunden-Woche für Assistenten und Oberärzte gekontert und neue Operationsmethoden skeptisch begrüsst. Vorsichtig wird an der Gegenwart geschnuppert. Remakes zeigen, dass mit Einbezug der Vergangenheit Neues, Faszinierendes entstehen kann - als ältere Ausbildner sind wir ver- pflichtet, auch das «Alte» in einer Art weiterzugeben und zu vermitteln, damit neue Trends in ihren Anfängen und in ihrer Logik verstanden werden können (innerhalb der gesetzlichen Arbeitszeit, wieso fehlt da ab und zu einfach die Zeit?). Und am Schaum (foam-sclerotherapy) in der Varizenchirurgie schnuppern, mit Interesse (und einem selbstzufriedenen Lächeln) die neue Schraube und das neue Konzept der (wieder) geringen Instabilität der DLS (dynamic locking screw) anschauen - das sollten wir. Aber eine gewisse Skepsis behalten, auch einmal einen warnenden Finger erheben - das dürfen wir (auch). Nicht jedes Remake ist ein Erfolg. Anna Karenina, Edith Piaf und unserer ärztlichen Tätigkeit ist er zu wünschen. 